\title{
Decrements in one-way avoidance learning following septal lesions in rats'
}

JOHN KENYON, FAIRFIELD UNIVERSITY

E. E. KRIECKHAUS, YALE UNIVERSITY

\begin{abstract}
Whereas septal lesions in the rat have repeatedly been found to enhance acquisition of the two-way conditioned avoidance response, it was shown in the present study that acquisition of the one-way avoidance response was attenuated following septal lesions. It is suggested that a parsimonious explanation for this and other findings relevant to effects of septal lesions on fear motivated behavior is that septal lesions reduce fear.
\end{abstract}

\section{Problem}

It is well established (King, 1958; Tonini, Riccioni, Babbini, \& Missere, 1963; Garber \& Simmons, 1965; Krieckhaus, Simmons, Thomas, \& Kenyon, 1964; and Kenyon \& Krieckhaus, 1965) that, in rats, lesions in the septal area enhance acquisition of the two-way (shuttle) conditioned avoidance response (CAR). On the other hand, Vanderwolf (1964) reported observations suggesting that septal lesions retard acquisition of a one-way CAR. Since it is crucial for an understanding of the effects of septal lesions on fear motivated behavior to ascertain whether one-way and two-way avoidance responses are differentially affected by septal lesions, the effect of septal lesions on the one-way CAR was evaluated in the present study.

Also, to assess any increase in activity or inability to inhibit responding, amount of activity in the avoidance apparatus was evaluated prior to training.

Finally, to show that the animals used here were not different from those used in previous experiments which showed enhanced two-way acquisition, the animals were also trained in a two-way CAR following their one-way training.

\section{Method}

Fifty-six male hooded rats, weighing 190-200 gm at time of surgery, were used. The experimental group consisted of 22 rats with lesions in the septal area. The control group of 34 rats consisted of 10 sham-operated (the electrode was inserted into the septal region but no current was passed), 10 rats which received only the nembutal anesthesia, and 14 rats which received none of the above procedures. Histological and surgical procedures were the same as those employed by Kenyon \& Krieckhaus (1965) except that in the present study the lesioning current of 2 ma was passed for $10 \mathrm{sec}$.

To eliminate the hyperirritability following septal lesions, all rats were housed in community cages, with five to six rats per cage, for the first 14 days following surgery. On the 15th day, each rat was given 20 trials of one-way avoidance training; and then, 5 to 10 days

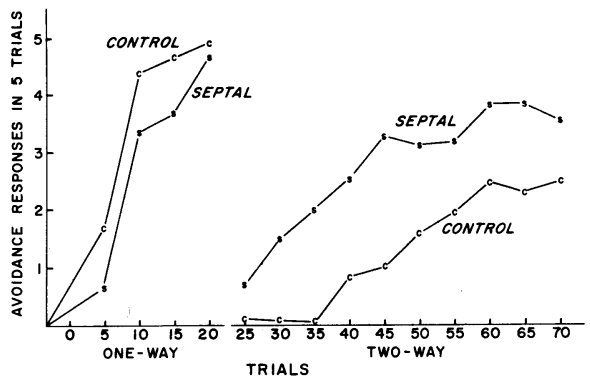

Fig. 1. Acquisition of the one-way and two-way CAR.

later, each rat was given 50 trials of two-way avoidance training, again in 1 day.

Apparatus and training procedures for the two-way task were the same as those employed by Kenyon \& Krieckhaus (1965). The one-way training procedure was the same as the two-way except that prior to testing on the first day the rat was left in the apparatus for $5 \mathrm{~min}$. and the number of spontaneous crossings from one side to the other was taken as a measure of spontaneous activity. Also, after each trial the animal remained in the safe side for $30 \mathrm{sec}$. and was then returned to the left side. Shock was administered only in the left side of the apparatus and the right side was always safe.

\section{Results}

The septal lesions were similar to those reported earlier (Krieckhaus et al, 1964) except that they were slightly less extensive. All lesions involved both lateral and medial septal nuclei and often extended into the fornix complex as well. There was no detectable relationship between locus of the lesions within the septal area and differences in behavior.

The three control groups did not differ significantly on any behavioral measures. They were combined and their acquisition of the one-way CAR is compared to that of the rats with septal lesions in Fig. 1. It is apparent that the rats with septal lesions showed poorer acquisition of the one-way CAR. Their median number of CARs in 20 training trials (13) was significantly less $(U=106 ; t=4.63 ; p<.001)$ than that of the control group (16). It is also clear from Fig. 1 that on the twoway $C A R$ the septal lesioned rats were far superior to the controls $(t=4.66 ; \mathrm{df}=53 ; \mathrm{p}<.001)$.

The rats with septal lesions did not appear to be more active than normals: number of spontaneous crossings before avoidance training did not differ between the two groups. Also, by the time the rats were trained, hyperirritability, evaluated by picking up the animal, was no longer in evidence in any of the lesioned animals. 


\section{Diseussion}

Results of this experiment clearly indicate that the enhanced acquisition of the CAR following septal lesions, found repeatedly with the two-way procedure, is not present with the one-way procedure. The hypothesis presented by Krieckhaus et al (1964) and Kenyon \& Krieckhaus (1965) that septal lesions attenuate fear-elicited competing responses, such as freezing, cannot, in its present form, explain this finding. Vanderwolf (1964) has suggested that septal lesions not only suppress freezing or non-movement, but also produce "some secondary form of impairment" which could explain the poor acquisition of the one-way CAR. In the case of the two-way CAR, this secondary impairment would presumably be offset by the enhancement due to attenuated competing responses.

However, in the interest of parsimony, we suggest an alternate hypothesis; namely, that septal lesions attenuate fear. Thus the poorer one-way CAR acquisition would simply be attributable to reduced motivation (less fear). Since freezing and other competing responses are directly related to strength of fear (Brush, Mook, \& Davis, 1960; Krieckhaus, Miller, \& Zimmerman, 1965), this decrease in fear would also attenuate the strength of the competing responses. Since there is ample evidence that decreased fear actually improves acquisition of the two-way CAR (Davis, Mook, \& Brush, 1958; Moyer \& Korn, 1964; and Krieckhaus et al, 1965) it appears that with the two-way CAR attenuation of the competing responses more than offsets the reduction in motivation. Thus the hypothesis that septal lesions reduce fear would predict enhanced two-way CAR acquisition-which is the case.

This hypothesis is also consistent with the studies discussed by Krieckhaus (1964) and Harvey, Lintz, Jacobsen \& Hunt (1965) in which lesions of the septal area have been found to attenuate a pronounced manifestation of fear-the conditioned emotional response (CER), and is also consistent with the studies discussed by McCleary, Jones \& Ursin (1965) in which septal lesions reduced the effectiveness of punishment in a passive avoidance situation.. Although in many of these studies, the strength of fear was evaluated against a thirst motivated response, and the results are thus confounded with increased water consumption (Harvey et al, 1965), several studies which have not used appetitively motivated behavior (Liss, 1964; Brady \& Nauta, 1953; Zucker \& McCleary, 1964) have also demonstrated reduced effectiveness of punishment or decrements in the CER, following septal lesions.

Finally, both Brady \& Conrad (1960) and Goldstein (1962) report that electrical stimulation of the septum (which appears to affect fear motivated behavior as septal lesions do) significantly suppresses the CER. This effect could be attributed to the stimulation either suppressing fear or directly suppressing the competing responses. However, on the first trial following removal of the stimulation the experimental animals still exhibited much less of a CER than the controls and subsequently showed a normal learning curve for the CER. This clearly suggests that septal stimulation had been attenuating fear or at least its conditionability, and that freezing had been reduced only indirectly.

It should be noted that the phenomenon of both lesions and stimulation of the septum having the same effect on fear-motivated behavior, suggested by Krieckhaus et al (1964), is further substantiated by the results of Kasper (1964) who found that septal stimulation also attenuated the ability of rats to refrain from approaching food when they were punished for doing so (passive avoidance). Similar results have been reported for septal lesions (Kaada, Rasmussen \& Kveim,
1962). Kasper further reported that the rats with septal stimulation showed significantly less freezing than the controls. This is in spite of the fact that the rats with septal stimulation were receiving significantly more shocks than the controls. This data suggests that even temporary septal lesions produced by electrical stimulation also reduce fear.

\section{Referenees}

BRADY, J. V. \& CONRAD, D. G. Some effects of limbic system selfstimulation upon conditioned emotional behavior. J. comp. physiol. Psychol., 1960, 53, 128-137.

BRADY, J. V. \& NAUTA, W. J. H. Subcortical mechanisms in emotional behavior: affective changes following septal fore-brain lesions in the albino rat. J. comp. physiol. Psychol., 1953, 46, 339-346.

BRUSH, F. R., MOOK, D. G. \& DAVIS, C. G. Conditioned and unconditioned responses as function of shock intensity. Paper read at Eastern Psychological Association, New York, April, 1960.

DAVIS, C. G., MOOK, D. G. \& BRUSH, F. R. Acquisition of avoidance behavior as a function of shock intensity using a trace conditioning procedure. Amer. Psychologist, 1958, 13, 419 (Abstract).

GARBER, E. E. \& SIMMONS, H. J. Septal lesions in rats facilitate two-way avoidance performance by reducing conflict. Paper read at Eastern Psychological Association, New York, April, 1965. GOLDSTEIN, R. Effects of non-contingent septal stimulation on: CER learning, response to foot shock, and electrical activity of muscle. Ph. D. Dissertation, Univ. Illinois, 1962.

HARVEY, J. A., LINTS, C. E., JACOBSEN, L. E. \& HUNT, H. F. Effects of lesions in the septal area on conditioned fear and discriminated instrumental punishment in the albino rat. J. comp. physiol. Psychol., 1965, 59, 37-48.

KAADA, B. R., RASMUSSEN, E. W. \& KVEIM, O. Impaired acquisition of passive avoidance behavior by subcallosal, septal, hypothalamic, and insular lesions in rats. J. comp. physiol. Psychol., 1962, 55, 661-670.

KASPER, P. Attenuation of passive avoidance by continuous septal stimulation. Psychon. Sci., 1964, 1, 219-220.

KENYON, J. \& KRIECKHAUS, E. E. Enhanced avoidance behavior following septal lesions in the rat as a function of lesion size and spontaneous activity. J. comp. physiol. Psychol., 1965, 59, 466-468.

KING, F. A. Effects of septal and amygdaloid lesions on emotiona! behavior and conditioned avoidance responses in the rat. J. nerv. ment. Dis., 1958, 126, 57-63.

KRIECKHAUS, E. E., MILLER, N. E.\& ZIMMERMANN, P. Reduction of freezing behavior and improvement of shock avoidance by d-amphetamine. J. comp. physiol. Psychol., in press.

KRIECKHAUS, E. E., SIMMONS, H.J., THOMAS, G.J. \& KENYON, J. Septal lesions enhance shock avoidance behavior in the rat. Exp. Neurol., 1964, 9, 107-113.

LISS, P. H. The role of the hippocampus and septum in response inhibition. Ph. D. Dissertation, McGill University, 1964.

MCCLEARY, R. A., JONES, C. \& URSIN, H. Avoidance and retention deficits in septal cats. Psychon. Sci., 1965, 2, 85-86.

MOYER, K. E. \& KORN, J. H. Effect of UCS intensity on the acquisition and extinction of an avoidance response. J. exp. Psychol., 1964, 67, 352-359.

TONINI, G., RICCIONI, M. L., BABBINI, M., \& MISSERE, G. Evaluation of central pharmacological action in rats with septal lesions. In Z. Votava, M. Horvath \& O. Vinar (Eds.), Psychopharmacological methods. Oxford: Pergamon. 1963, 106-114.

VANDERWOLF, C. H. Effect of combined medial thalamic and septal lesions on active-avoidance behavior. J. comp. physiol. Psychol., $1964,58,31-37$.

ZUCKER, I. \& MCCLEARY, R. A. Perseveration in septal cats. Psychon. Sci., 1964, 1, 387-388.

\section{Note}

1. This research was supported by Grant AP-17 from the National Research Council of Canada to McGill University; Grant MH02949 from the National Institute of Mental Health to Yale University; and by Institutional Grant GU-712 from the National Science Foundation to Fairfield University. 